\title{
PENINGKATAN HASIL BELAJAR KOGNITIF BIOLOGI MENGGUNAKAN MODEL PROBLEM BASE LEARNING BERBASIS POWTOON SISWA KELAS XII IPA 7 SMA N 1 METRO SEMESTER GANJIL TAHUN PELAJARAN 2017/2018
}

\author{
Hasbullah \\ SMA N 1 Metro \\ E-mail: aambio39@yahoo.com
}

\begin{abstract}
The development of Information and Communication Technology (ICT) in learning in schools makes the media not only fixated on using printed books, worksheets (LK) or modules only but can utilize technological sophistication in learning. In class XII IPA 7 of 2016/2017 school year has been using scientific-based worksheet on the metabolic material. The metabolic material is always a challenge in biology because this material is always considered material that is difficult for students. Metabolic cycles are explained using pictures, lessons are still considered unattractive and there are still many students who do not understand so that student learning outcomes are less than $56.25 \%$ of students who achieve minimum completeness criteria. This Class Action Research Objective is: To improve learning outcomes Biology Students in XII IPA 7 Senior High School $N 1$ of Metro Academic Year 2017/2018 by using a powtoon based problem base learning model. This type of research is CAR (Room Action Research) with stages consits of 1) planning, 2) reflecting, 3) doing / acting and repeating until learning indicators are reached. The conclusion of this study, the model of powtoon-based problem base learning can improve the learning outcomes of Biology students of Class XII IPA 7 N 1 Metro 1 Odd Semester Academic Year 2017/2018. At the beginning of the pre-PTK students who reach the minimum completeness criteria or students who are said to complete as much as $37.04 \% \%$ and increased by $25.46 \%$ in the first cycle, which amounted to $62.5 \%$. And it increased again in the second cycle as many as $25 \%$ of students completed to $87.5 \%$
\end{abstract}

Keywords: Learning Outcomes, Problem Base Learning, Powtoon Media

Seiring berkembangnya zaman, dalam dunia pendidikan juga selalu mengalami perubahan kurikulum dari masa ke masa. Di Indonesia sudah dilaksanakan pembelajaran menggunakan kurikulum 2013. Dimana kurikulum tersebut menekankan siswa untuk lebih aktif dalam berfikir secara ilmiah dan menuntut guru agar menguasai Information and Communication Technologi (ICT).
Perubahaan kurikulum yang selalu berubah-ubah tersebut merupakan dampak dari perkembangan globalisasi, guna mengembangkan mutu pendidikan agar dapat bersaing di dunia luar. Menurut Hidayangsih, dkk (2011) Era globalisasi dan keterbukaan informasi, misalnya internet membuat segala bentuk informasi menjadi sangat mudah didapat, bahkan sampai ke kota-kota kecil. Berdasarkan hal tersebut, era 
globalisasi semakin berkembang pada dunia teknologi yang dampaknya juga merambah pada dunia pendidikan. Salah satu nya media pembelajaran berbasis ICT yang pengembangannya menggunakan media online.

Terkait hal tersebut, maka diperlukan media untuk menyampaikan informasi. Media sangat penting sebagai penunjang untuk pemahaman siswa. Dimana dalam konteks Ilmu Pengetahuan dan Teknologi (IPTEK) yang selalu berkembang pesat, termasuk juga pada dunia pendidikan, sekolahsekolah pun memanfaatkan perkembangan IPTEK dengan baik. Sekolah kota maupun sekolah di desa sudah banyak yang menggunakan komputer, LCD, bahkan tenaga pendidik sudah banyak yang memiliki laptop masing-masing, sehingga dalam hal tersebut dalam penggunaan media tidak hanya terpaku menggunakan buku cetak, Lembar Kerja (LK) maupun modul saja, namun dapat memanfaatkan kecanggihan teknologi dalam pembelajaran.

Pada tahun ajaran 2016/2017 peneliti sudah menggunakan Lembar Kerja Peserta Dididk (LKPD) yang dikembangkan oleh peneliti sendiri, namun pada sub materi metabolisme, hasil belajar siswa masih kurang maksimal. Sub materi metabolisme selalu menjadi tantangan tersendiri dalam pembelajaran biologi, karena materi tersebut sudah menjadi momok menakutkan dalam pikiran siswa, siswa selalu menganggap materi metabolisme sulit karena terdapat banyak siklus-siklus kimia dalam prosesnya. LKPD yang dikembangkan peneliti memaparkan siklus-siklus tersebut dengan menggunakan gambar-gambar, ternyata masih banyak siswa yang kesulitan memahami gambar tersebut sehingga hasil belajar kurang maksimal. Hasil belajar kognitif siswa pada materi metabolisme Tahun Ajaran 2016/2017 dapat dilihat pada Tabel 1 berikut:

Tabel 1. Penilaian Harian siswa kelas XII IPA 7 Pra PTK

\begin{tabular}{|c|c|c|c|c|}
\hline No. & Nilai & Kriteria & $\begin{array}{c}\text { Jumlah } \\
\text { Siswa }\end{array}$ & Persentase \\
\hline 1 & $\begin{array}{l}\geq \\
75\end{array}$ & Tuntas & 10 & $37,04 \%$ \\
\hline 2 & $\begin{array}{l}< \\
75\end{array}$ & $\begin{array}{l}\text { Tidak } \\
\text { Tuntas }\end{array}$ & 17 & $62,96 \%$ \\
\hline & \multicolumn{2}{|c|}{ Jumlah } & 27 & $100 \%$ \\
\hline
\end{tabular}

Media alternatif yang dapat digunakan salah satunya melalui media audio-visual. Dengan media tersebut, diharapkan siswa dapat lebih memahami materi secara nyata dibandingkan dengan buku yang hanya menjelaskan konsep-konsep. Selain itu juga dapat membangkitkan minat dan memotivasi dalam merangsang kegiatan pembelajaran. Media audio-visual ini memanfaatkan dua indra sekaligus, yaitu indra penglihatan dan indra pendengaran, dimana indra penglihatan merupakan indra yang paling dapat diingat oleh siswa dibandingkan dengan indra yag lain. Salah satu media pembelajaran audio visual berbasis internet yang menarik 
adalah media pembelajaran berbasis powtoon.

Aplikasi powtoon yang memiliki fitur canggih dalam satu layar, yang dapat membuat berbagai animasi sesuai kebutuhan yang diperlukan. Dalam pembelajaran tersebut juga dikemukakan bahwa animasi memiliki banyak keunggulan seperti dapat menghilangkan kejenuhan dalam pembelajaran, membangkitkan gairah belajar, dan tentunya animasi dapat menarik perhatin siswa agar tetap fokus dalam proses belajar (Wirasasmita, 2015).

Selain media pembelajaran, Seorang guru pasti akan menyampaikan materi melalui model pembelajaran. Model pembelajaran merupakan rancangan pola pembelajaran yang dibuat guru agar pembelajaran menjadi lebih menarik, dan mudah dipahami siswa. Setiap guru di sekolah tentu menggunakan model pembelajaran dalam menyampaikan materi pembelajaran kepada siswa. Salah satunya yaitu Model pembelajaran Problem Based Learning (PBL) merupakan model pembelajaran berbasis masalah. Penerapan model pembelajaran berbasis masalah akan membuat siswa untuk mampu menganalisis materi pembelajaran dengan masalah yang diberikan. Penerapan model pembelajaran berbasis masalah didasari dengan suatu masalah yang akan membangkitkan rasa ingin tahu siswa terhadap pemecahan masalah yang diberikan sehingga perserta didik akan diajak untuk berfikir kritis dan aktif dalam menyelesaikan masalah. Berdasarkan pemaparan di atas, penulis akan melakukan penelitian tindakan kelas yang berjudul " Peningkatan hasil belaja kognitif biologi menggunakan model problem base learning berbasis powtoon siswa kelas XII IPA 7 SMA N 1 Metro Tahun Pelajaran 2017/2018"

\section{METODE}

Metode penelitian ini yaitu CAR (Room Action Research), atau yang sering kita kenal dengan Penelitian Tindakaan Kelas (PTK) dengan tahapan 1) merencanakan, 2) melakukan/tidakan, 3) merefleksi dan berulang sampai tercapai indikator pembelajaran.

\section{Tempat Penelitian}

Penelitian ini dilakukan di Sekolah SMA N 1 Metro pada kelas XII IPA 7 Tahun Pelajaran 2017/2018.

\section{Subyek Penelitian}

Subjek yang digunakan dalam penelitian ini adalah siswa kelas XII IPA 7 SMA N 1 Metro Tahun Pelajaran 2017/2018 dengan jumlah siswa 32 .

\section{Prosedur Penelitian}

Ada 4 tahapan dalam PTK ini yaitu, perencanaan tindakan, pelaksanaan tindakan, obervasi, dan refleksi. Untuk penjabarannya sebagai berikut:
a. Perencanaan Tindakan
Perencanaan tindakan yang dilaksanakan dalam tindakan ini adalah: 
1) Menyiapkan perangkat pembelajaran berupa sekenario pembelajaran, media, bahan dan alat, instrument obsevasi, evaluasi, dan refleksi.

2) Membuat desain pembelajaran yang menggunakan Model Problem Based Learning (PBL) berbasis powtoon.

3) Membentuk kelompok kecil sebanyak 8 kelompok, masingmasing kelompok berjumlah 4 orang. Anggota kelompok diupayakan bersifat heterogen dari kemampuan akademiknya agar terjadi saling membantu.

4) Mengadakan evaluasi belajar menggunakan tes untuk memperoleh nilai masingmasing individu.

\section{b. Pelaksanaan Tindakan}

Langkah-langkah proses pembelajaran model pembelajaran PBL pada Tabel 2.

Tabel 2. Kegiatan Pembelajaran PBL berbasis Powtoon

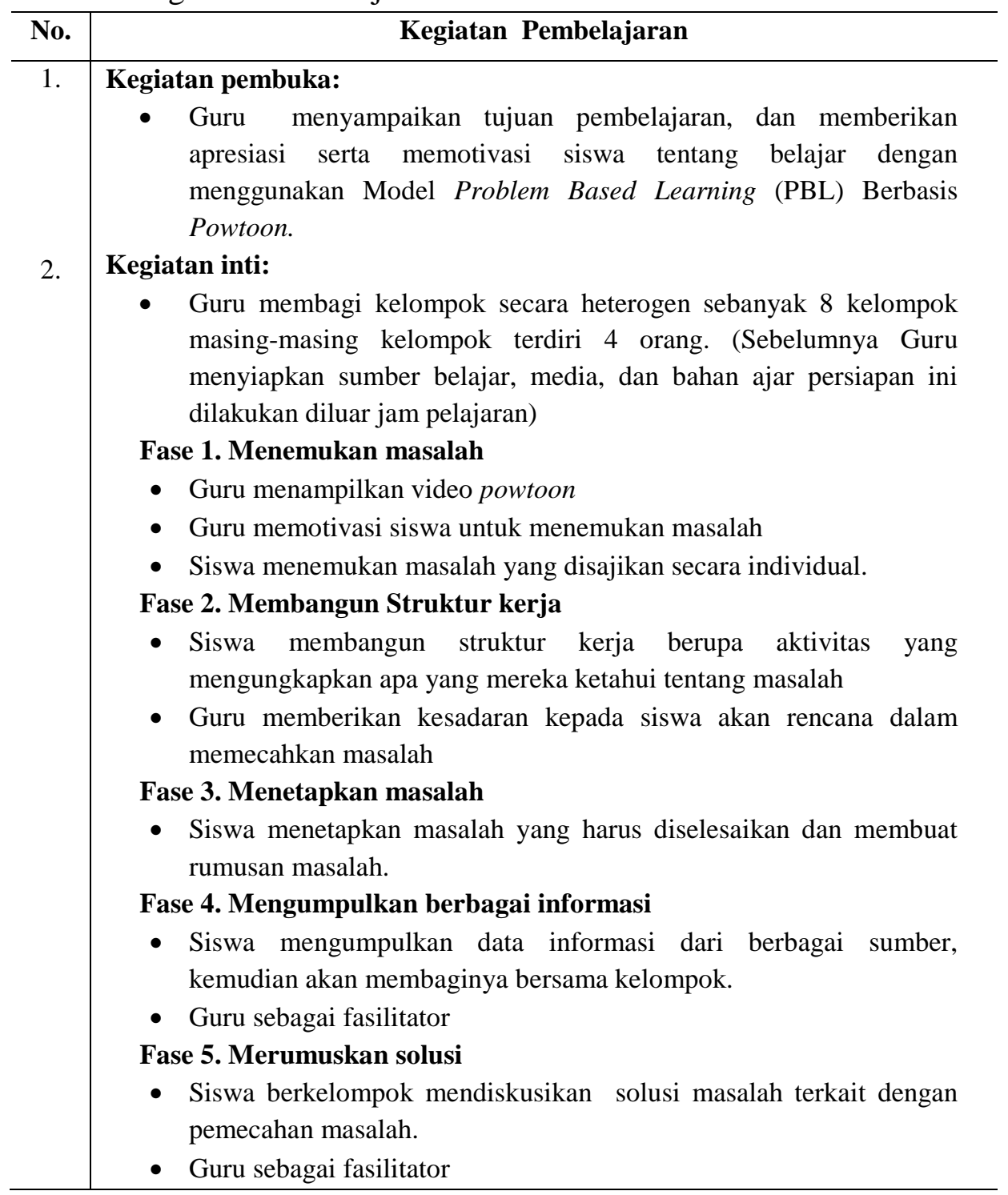




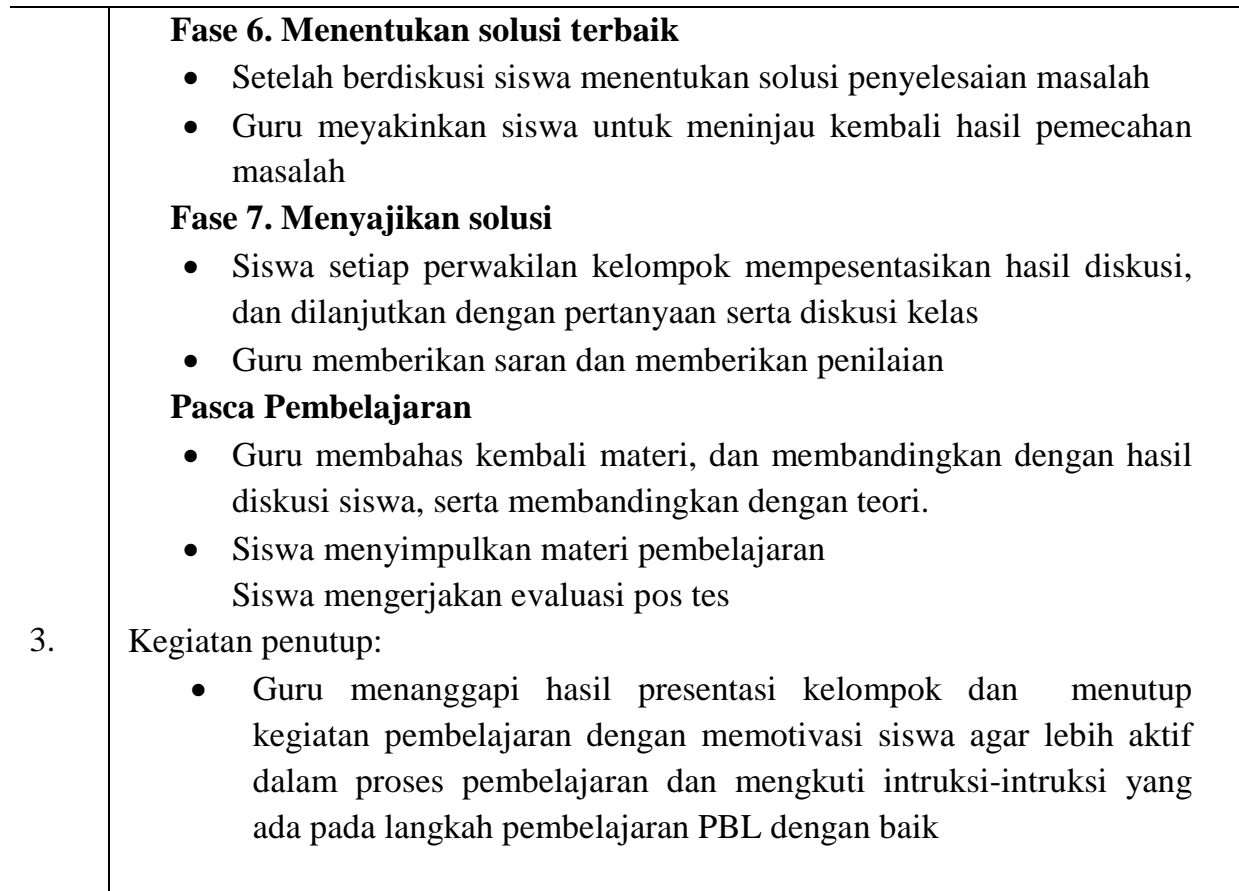

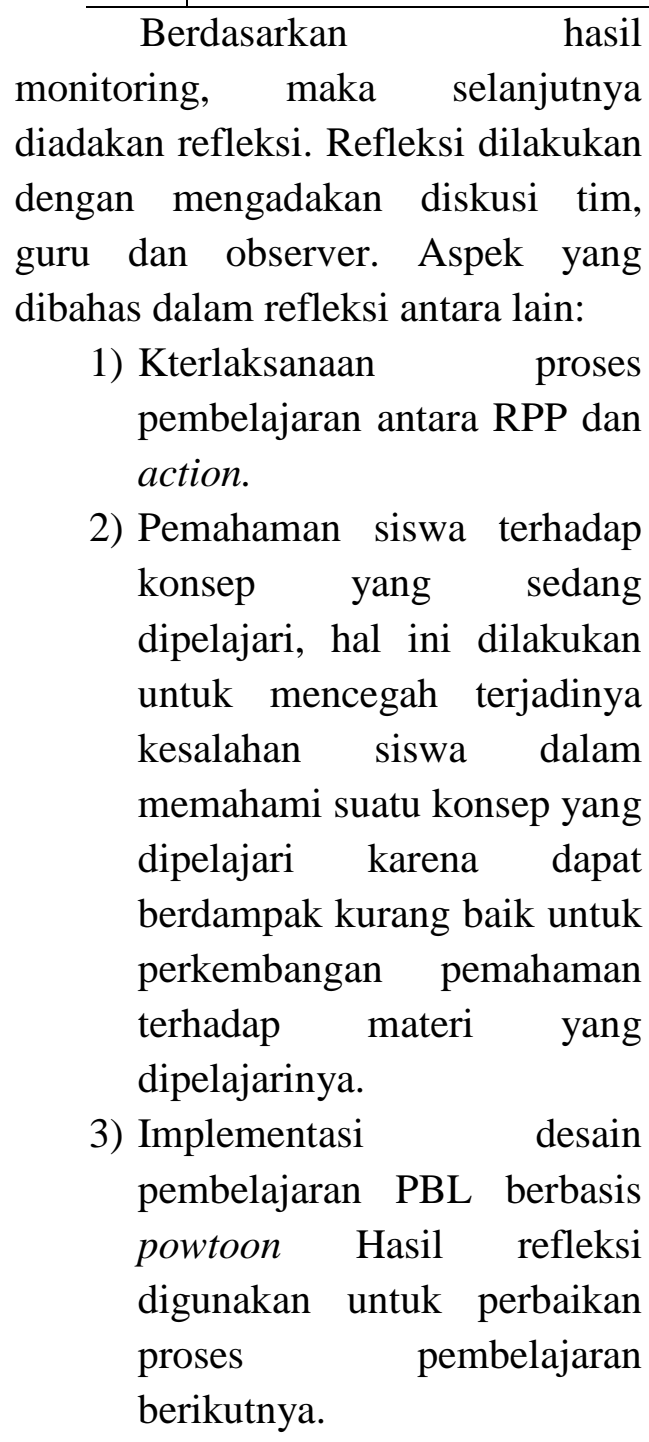

4. Teknik dan Instrumen

\section{a. Pengumpulan Data}

Tes

Instrumen tes dalam penelitin ini digunakan untuk memperoleh data hasil belajar siswa. tes ini digunakan pada saat awal siklus dan akhir siklus untuk mengetahui peningkatan hasil belajar siswa. Jenis instrumen tes yang digunakan adalah pilihan ganda.

b. Analisis data

Pengukuran Kemantapan Instrumen menggunakan validitas validitas isi (content validity) yaitu validitas yang menguji ketepatan daripada suatu tes ditinjau dari isi tes. dan reliabilitas menggunakan analisis data KR 20 dengan rumus:

$V t=\frac{\sum X^{2}-\frac{\left(\sum X\right)^{2}}{N}}{N}$ 


$$
\begin{array}{ll}
r 11=\left(\frac{n}{n-1}\right)\left(\frac{V t-\sum p q}{V t}\right) & : \text { varians } \\
\mathrm{Vt} \quad & \begin{array}{l}
\text { jumlah dari jumlah } \\
\sum X^{2}
\end{array} \\
& \text { kuadrat setiap skor } \\
\left(\sum X\right)^{2} \quad: \text { jumlah kuadrat skor } \\
& \text { total } \\
\mathrm{N} \quad: \text { jumlah siswa }
\end{array}
$$

Adapun interpretasi mengenai besarnya skala korelasi menurut Arikunto (2010) adalah:

a) Antara 0,800 sampai dengan 1,00 : sangat tinggi

b) Antara 0,600 sampai dengan 0,800 : tinggi

c) Antara 0,400 sampai dengan 0,600 : cukup

d) Antara 0,200 sampai dengan 0,400 : rendah

e) Antara 0,000 sampai dengan 0,200 : sangat rendah

\section{Indikator Keberhasilan}

Tindakan penelitian dikatakan berhasil apabila persentase setiap keterampilan telah mencapai target. Target penelitian tindakan kelas ini adalah hasil belajar siswa bisa mencapai nilai KKM $\geq 75$ sebanyak $80 \%$.
HASIL

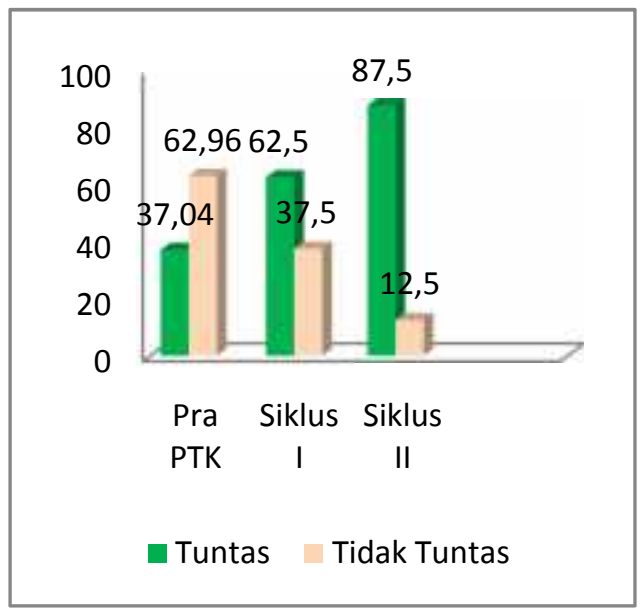

Gambar 1. Diagram Batang

Peningkatan Hasil Belajar Siswa

Berdasarkan Gambar 1 di atas, Hasil penelitian pra-PTK sampai akhir siklus II diketahui bahwa terjadi peningkatan hasil belajar siswa kelas XII IPA 7 semsester ganjil SMA Negeri 1 Metro Tahun Pelajaran 2017/2018. Pada awal pra PTK siswa yang mencapai KKM atau siswa yang dikatakan tuntas sebanyak $37,04 \% \%$ dan meningkat sebanyak $25,46 \%$ pada siklus I, yaitu sebesar $62,5 \%$. Dan meningkat lagi pada siklus II sebanyak $25 \%$ siswa yang tuntas menjadi $87,5 \%$.

\section{PEMBAHASAN}

Peningkatan terlihat signifikan, hal tersebut terjadi karena menggunakan model pembelajaran PBL berbasis powtoon. Penerapan model pembelajaran PBL juga meningkatkan minat belajar siswa untuk mengikuti proses pembelajaran, dan juga mendorong siswa lebih aktif dalam menyelesaikan permasalahan 
pembelajaran dengan ide-ide mereka.

Seperti pada penelitian Septian (2017) pembelajaran dengan model Problem Based Learning (PBL) adalah pembelajaran yang memberikan tantangan bagi siswa untuk mencari solusi dari permasalahan dunia nyata (terbuka) secara induvidu maupun kelompok. Alasan menggunakan model problem based learning $(\mathrm{PBL})$ agar siswa saat dihadapkan suatu permasalahan dapat menyelesaikannya, sehingga dalam pembelajaran dapat aktif dalam memberikan tanggapan, ide dan argumen.

$$
\text { Senada dengan pendapat }
$$
Wirasasmita (2015) Aplikasi powtoon memiliki banyak animasi dan keunggulan seperti dapat menghilangkan kejenuhan dalam pembelajaran, membangkitkan gairah belajar, dan tentunya animasi dapat menarik perhatian siswa agar tetap fokus dalam proses belajar. Pemakaian media pembelajaran dalam proses belajar mengajar dapat membangkitkan keinginan dan minat yang baru, membangkitkan motivasi dan rangsangan kegiatan belajar mengajar, dan bahkan membawa pengaruh-pengaruh psikologis terhadap siswa (Arsyad, 2014)

Bangkitnya semangat dan motivasi siswa membuat siswa bersemangat belajar, materi pembelajaran akan mudah dimengerti siswa karena tidak hanya mendengarkan dan menulis, namun materi pembelajaran langsung direalisasikan kedalam penyelesaian masalah secara nyata, pada materi katabolisme dan anabolisme cara kerja ezim dipraktekan secara langsung, siklus respirasi aerob dan anaerob juga diamati dengan video powtoon untuk mengumpulkan informasi dalam penyelesaian permasalahan dalam LK.

Semua siswa terlibat aktif, dalam proses penyelesaian masalah karena penerapan model pembelajaran PBL meningkatkan motivasi belajar siswa, motivasi belajar siswa yang meningkat maka keaktifan siswa dalam mengikuti proses pembelajaran meningkat pula, hal ini sesuai dengan Devi (2014:126-135) menyatakan bahwa motivasi siswa berbanding lurus dengan keaktifan siswa. Keaktifan siswa dalam mengikuti pembelajaran, meningkatkan kemampuan siswa dalam menguasai materi metabolisme lebih mudah dimengerti sehingga hasil belajar kognitif siswa menjadi meningkat, hal ini seiring dengan penelitian Ibrahim (2017:9-20) model pembelajaran PBL yang diberlakukan pada kelas eksperimen dapat meningkatkan hasil belajar siswa pada mata pelajaran ekonomi di SMA Negeri 1 Palu lebih tinggi dibandingkan dengan Model konvensional. Berbagai analisis kritis kenggulan dan kelebihan model pembelajaran PBL berbasis Powtoon dari berbagai kajian penelitian ilmiah di atas, tentunya membuat hasil belajar siswa dapat meningkat. 


\section{KESIMPULAN}

Berdasarkan hasil penelitian tindak kelas yang dilakukan dengan menggunakan model pembelajaran Problem Base Learning berbasis Powtoon, maka dapat disimpulkan bahwa: Problem Base Learning berbasis Powtoon dapat meningkatkan hasil belajar Biologi Siswa Kelas XII IPA 7 SMA N 1 Metro Semester Ganjil Tahun Pelajaran 2017/2018. Pada awal pra PTK siswa yang mencapai KKM atau siswa yang dikatakan tuntas sebanyak $37,04 \% \%$ dan meningkat sebanyak $25,46 \%$ pada siklus I, yaitu sebesar $62,5 \%$. Dan meningkat lagi pada siklus II sebanyak $25 \%$ siswa yang tuntas menjadi $87,5 \%$.

\section{DAFTAR RUJUKAN}

Arikunto, S. 2010. Prosedur Penelitian Suatu Pendekatan Praktik. Jakarta: PT Rineka Cipta.

Arsyad, A. 2014. Media Pembelajaran. Jakarta: PT Rajagrafindo Persada.

Devi, A., S. Mulyani, \& Haryono. 2014. Perbedaan Implementasi Pembelajaran Kimia Model Problem Based Learning (PBL) Materi Stoikiometri Kelas X Mia SMA Negeri Di Kota Surakarta Tahun Ajaran 2013/2014, Jurnal Pendidikan Kimia (JPK), 3(4) : 126-135.
Hidayangsih, P.S., D. H. Tjandrarini, R. Mubasyiroh \& Supanni 2011. Faktor-faktor yang berhubungan dengan perilaku berisioko remaja di kota makasar tahun 2009. Bul.Penelit. Kesehatan. 39(2), 88-98.

Ibrahim, A. S. E., Suyuti \& L. Nadjamuddin. 2017. Pengaruh Model Pembelajaran Problem Based Learning terhadap Hasil Belajar Mata Pelajaran Ekonomi Pada Siswa SMA Negeri 1 Palu. Jurnal Katalogis. 5(4), 9-20.

Septian,Ary dan Rizki Andi. 2017. Penerapan Model Problem Based Learning(PBL) terhadap Kemampuan Berfikir Kreatif Matematis Siswa. Jurnal Prisma Universitas Suryakancana. 6(1),162-172.

Wirasasmita, H. R., \& Y. K. Putra. 2015. Pengembangan Media pembelajaraan video tutorial interaktif menggunakan aplikasi camtasia studio dan macromedia flash. Jurnal Educatio. 10(2), 262-279. 